\title{
Effects of Morning versus Evening Administration of Perindopril on the Circadian Control of Blood Pressure in Cameroonian Type 2 Diabetes Individuals: A Crossover Randomized Trial
}

\author{
Liliane Mfeukeu Kuate ${ }^{1 \neq}$, Helene Ornella Bongha Ondoa ${ }^{1 \neq}$, Jean-Claude Katte ${ }^{2}$, Aurel \\ Tiakouang Tankeu, ${ }^{1}$, Mireille Claudia Abeng Bokam ${ }^{1}$, Andre Michel Bimbai ${ }^{3}$, Ahmadou \\ Musa Jingi ${ }^{1}$, Chris Nadège Nganou-Gnindjio ${ }^{1}$, Mesmin Yefou Dehayem ${ }^{4}$, Francois Folefack \\ $K^{K a z e}{ }^{1}$, Jean Claude Mbanya $^{1,5^{*}}$, Andre Pascal Kengne ${ }^{5}$ and Eugene Sobngwi ${ }^{1,5,6}$
}

${ }^{1}$ Department of Internal Medicine and Specialities, Faculty of Medicine and Biomedical Sciences, University of Yaounde 1, Yaounde, Cameroon

${ }^{2}$ Department of Public Health, Faculty of Medicine and Biomedical Sciences, University of Yaounde 1, Yaounde, Cameroon ${ }^{3}$ Faculte de Medecine, Universite Paris Sud, France

${ }^{4}$ Non-Communicable Diseases Research Unit, South African Medical Research Council and University of Cape Town, Cape Town, South Africa

${ }^{5}$ National Obesity Center, Yaounde Central Hospital, Yaounde, Cameroon

${ }^{6}$ Laboratory for Molecular Medicine and Metabolism, Biotechnology Center, University of Yaoundé I, Yaoundé, Cameroon ${ }^{\ddagger}$ Equal Contribution.

*Corresponding author: Dr. Jean-Claude Katte, MD, Department of Public Health, Faculty of Medicine and Biomedical Sciences, University of Yaoundé 1, Yaoundé, Cameroon, Tel: +237-677587929

\begin{abstract}
Background: Renin-angiotensin system antagonists are the mainstays of blood pressure (BP) lowering strategies in people with diabetes. Perindopril a long half-life Angiotensin Converting Enzyme (ACE) inhibitor offers the advantage of a single daily dose, usually empirically taken in the morning. We therefore aimed to assess the influence of time of administration on the effect of Perindopril on circadian BP in type 2 diabetes (T2D) individuals with previously untreated stage 1 hypertension.

Methods: Twenty T2D patients (9 being women) with a mean age of 58.7 years, newly diagnosed with stage 1 hypertension, were randomly allocated to receive perindopril $10 \mathrm{mg} /$ day as monotherapy either in the morning or in the evening for 28 days, with crossover without washout period on day $29^{\text {th }}$ and additional 28 days follow-up. A 24hour ambulatory BP monitoring (ABPM) was performed at baseline, days 28 and 56 . This study was retrospectively registered having a trial registration: ClinicalTrials.gov Identifier: NCT03393715. January 8, 2018.
\end{abstract}

\begin{abstract}
Results: Median diagnosed duration of diabetes was 2.0 years. At baseline, mean 24-hour systolic and diastolic BP were $137.0 \mathrm{mmHg}$ and $84.5 \mathrm{mmHg}$, and mean albumin/ creatinine ratio (ACR) was $132.6 \mathrm{mg} / \mathrm{g}$. There was no difference in the 24-hour systolic blood pressure pattern between the patients on morning perindopril and patients on evening perindopril $(p=0.61)$. The chronotherapeutic scheme did not influence neither ACR $(p=0.58)$ nor uric acid level $(p=0.32)$. However, the administration of $10 \mathrm{mg}$ Perindopril lowered the ACR in both treatment allocation sequences; with an overall treatment effect of -41.7 (95\% Cl: -92.6 to 9.2$) \mathrm{mg} / \mathrm{g}$.

Conclusions: The morning administration of perindopril did not prove to be superior to night time regimen for BP control in this group of sub-Saharan type 2 diabetes patients with stage 1 hypertension. However, the administration of perindopril seems to lower the ACR which is suggestive of the reno-protective effect of ACE inhibitors in patients presenting with hypertension and type 2 diabetes.
\end{abstract}

Citation: Kuate LM, Ondoa HOB, Jean-Claude K, Tankeu AT, Bokam MCA, et al. (2019) Effects of Morning versus Evening Administration of Perindopril on the Circadian Control of Blood Pressure in Cameroonian Type 2 Diabetes Individuals: A Crossover Randomized Trial. Int Arch Cardiovasc Dis 3:014 Accepted: February 23, 2019; Published: February 25, 2019

Copyright: (C) 2019 Kuate LM, et al. This is an open-access article distributed under the terms of the Creative Commons Attribution License, which permits unrestricted use, distribution, and reproduction in any medium, provided the original author and source are credited. 


\section{Keywords}

Type 2 diabetes, ACE inhibitor, Perindopril, Circadian control, Blood pressure

\section{List of Abbreviations}

ACR: Albumin/Creatinine Ratio; ABPM: Ambulatory Blood Pressure Monitoring; ACE: Angiotensin Converting Enzyme (ACE); BP: Blood Pressure; DBP: Diastolic Blood Pressure; SBP: Systolic Blood Pressure; PP: Pulse Pressure; T2D: Type 2 Diabetes (T2D)

\section{Background}

Hypertension is frequently associated with diabetes, with over half of individuals with diabetes also having hypertension [1]. This combination is associated with increased cardiovascular morbidity and mortality. For instance, about $75 \%$ of cardiovascular deaths in diabetes may be attributable to hypertension [2]. Therefore, achieving tight blood pressure (BP) control in diabetes is important for preventing vascular complications $[3,4]$. Just like in the general population, optimal BP control in diabetes goes beyond achieving targets systolic (SBP) and diastolic (DBP) BP as measured in routine clinical encounters, to include achieving optimal values of all BP components during the entire nychthemeron; sine qua none condition to minimize the risk of cardiovascular complications [4]. This emphasizes the importance of out-of-office BP measurement and particularly ambulatory BP measurement (ABPM) in people with diabetes [5]. In addition to SBP and DBP values, ABPM provides an overview of the circadian $B P$ control with nocturnal BP and MAP values, which are powerful predictors of cardiovascular risk in people with diabetes [6-8]. Up to $75 \%$ of people with type 2 diabetes have increased nocturnal BP values (also known as nondipping) [9]; phenomenon captured only by ABPM, and which is associated with high cardiovascular risk [10]. The increased nocturnal BP value is as a result of the upregulation of the RAAS common in diabetes. This upregulation of the RAAS in patient with diabetes comes as a result of an increase in plasma renin activity, mean arterial pressure, and general renal vascular resistance due to hyperglycemia [11]. Clinical practice guidelines are unanimous on the pivotal role of angiotensinconverting enzyme inhibitors (ACEIs) and angiotensin receptors antagonists in BP lowering strategies in people with diabetes [12]. It has been suggested that compared to morning ingestion, bedtime ingestion of more than one antihypertensive drug could induce a better reduction of incident cardiovascular events in type 2 diabetes patients [13]. Perindopril is a long acting ACEI, which displays similar pharmacodynamic properties to other agents in this class. It is a prodrug hydrolyzed to the active metabolite after absorption allowing once daily administration with adequate 24hour action [14]. Whether this translates into similar BP control irrespective of when the daily dose of perindopril is taken, remains unknown, although empirically this dose is generally absorbed in the morning. Accordingly, we conducted a clinical trial to investigate the chronotherapeutic effect of the administration of perindopril on BP control in diabetic individuals with stage 1 hypertension.

\section{Methods}

\section{Ethical considerations}

The study protocol was approved by the Institutional ethics research committee of the Faculty of Medicine and Biomedical Sciences (University of Yaounde 1, Cameroon). The Cameroon National Ethics Committee for Research in Human Health provided the ethical clearance for the trial.

\section{Design}

We carried out a prospective single blinded 2-sequence, 2-period, 2-treatment regimens randomised uniform $A B \mid B A$ crossover clinical trial, conducted over a six-month period from December 2015 to May 2016. There was no change in protocol during the study.

\section{Centers and patients}

The study population consisted of type 2 diabetic individuals all aged greater than 18-years-old, selected at the National Obesity Center of the Yaoundé Central Hospital (Cameroon), which has been described in details previously [15]. Only patients with a normal creatinine clearance and newly diagnosed and untreated stage 1 hypertension were included. Stage 1 hypertension was defined as 130-139 and/or 80-89 mmHg [16]. See the study flow diagram shown as Figure 1.

\section{Randomization and blinding}

The allocation sequence was randomly generated. The lead investigator (HOBO) enrolled the participants, while a second investigator (MCAB) was only responsible for generating the allocation sequence, assigning participants to their groups, and dispensing perindopril $10 \mathrm{mg}$ as needed. Our study population was divided into two groups by randomization using a simple and restricted method of blocks, which consisted of drawing one out of two of non-distinguishable counters from a non-transparent bag without replacement, every counter being either red or blue. Patients were assigned to one group or other depending on the color of the ball drawn [17]. Every patient drawing a red color was assigned to the first group (A) that received perindopril during morning for the first 28 days and in the evening for the last 28 days of the study. The second group (B) consisted of participants who drawn a blue ball. They received perindopril at the evening for the first 28 days, then switched to morning dose at mid follow-up.

\section{Procedure}

Patients were verbally invited by the investigator to 


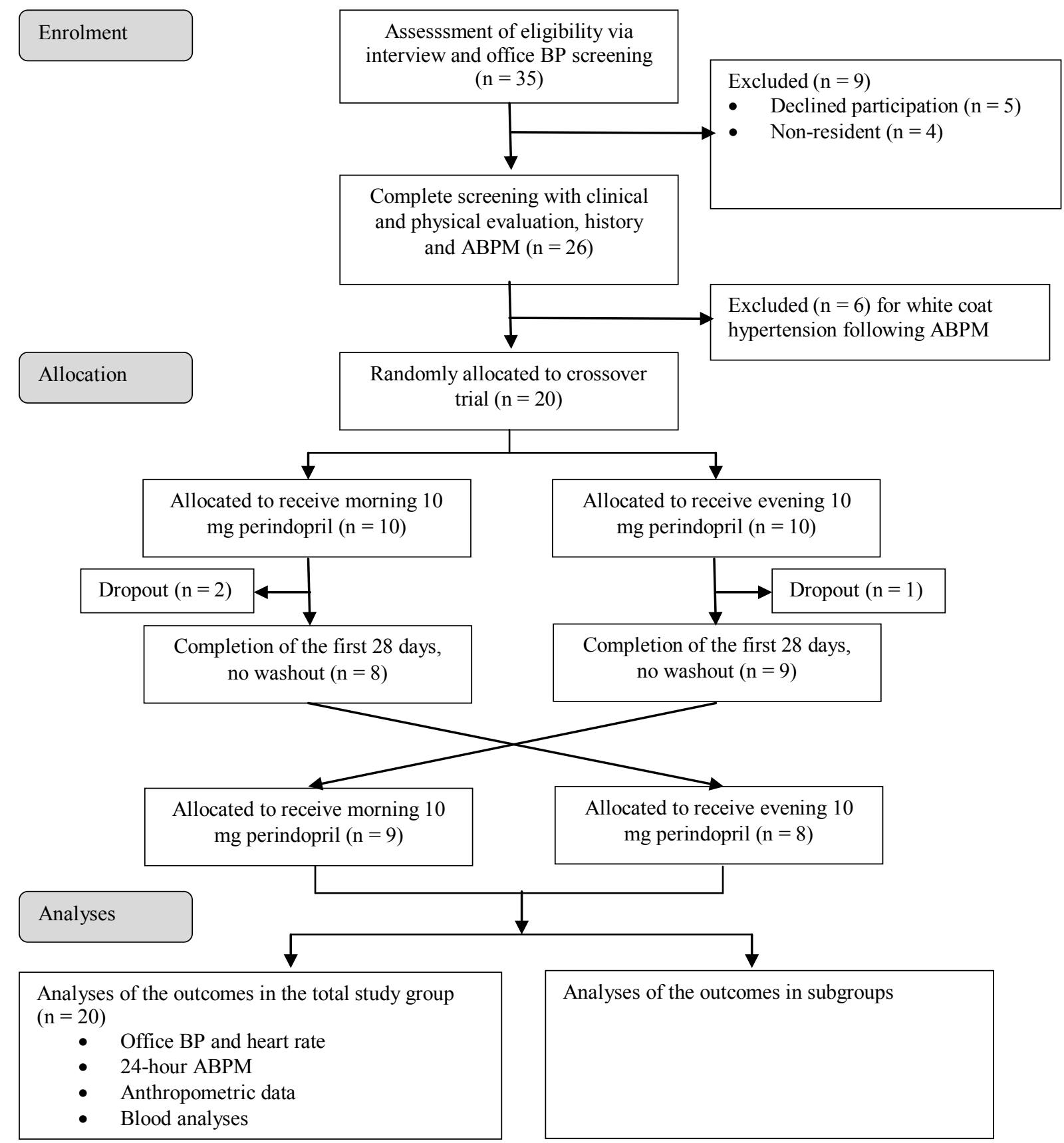

Figure 1: Study flow diagram of participants through the study.

the National Obesity Center of the Yaounde Central Hospital. Then, those having a stage 1 hypertension based on office blood pressure were selected for inclusion in the study. At the inclusion visit, participants received all information concerning the study and provided their written informed consent before final inclusion. Then, a clinical examination was performed during which, three serial office blood pressure measurements were taken five minutes apart in the sitting position from non-dominant arm using an automated sphygmomanometer Omron HEM-705 CP (Omron Corporation, Tokyo, Japan). The average of the three measurements was used as clinical BP during analyses. Weight to the nearest $0.5 \mathrm{~kg}$ was measured with participant lightly dressed, using a TANITA (TANITA Corporation 1-14-2 Maeno-cho, Tabashi-ku, Tokyo-
Japan) scale. Height to the nearest $0.5 \mathrm{~cm}$ was measured in the upright position using a Leicester stadiometer, and body mass index (BMI in $\mathrm{kg} / \mathrm{m}^{2}$ ) calculated as weight $(\mathrm{Kg}) /[$ height $(\mathrm{m}) \times$ height $(\mathrm{m})]$.

Waist circumference was measured at the horizontal plane midway between the lower rib margin and the iliac crest with a measuring tape. During this visit, each patient was informed of his randomized treatment regimen, by the second member of the research team. A spot urine sample was taken for the estimation of the urinary albumin excretion using turbidimetry method, and $10 \mathrm{ml}$ of venous blood sample drawn plasma creatinine, potassium and uric acid assays. Creatinine clearance was estimated using the Modification of Diet in Renal Disease (MDRD) formula [18]. ABPM was performed using a light weight device (i-mapa CE 004 
1.1 TM High-tech Medical St Louis, Paris). Readings were obtained automatically at 15-min intervals during the day time defined from 07:00 to 22:00 and every $30 \mathrm{~min}$ from 22:00 to 07:00. This interval was set using a fix clock time but control with a personal diary for each patient. After, detailed information on device functioning, two readings were activated in the laboratory to ensure functionality before the patient left. Then, he was asked to continue his normal daily activities. A minimum of $70 \%$ of valid measures was required for interpretation. The participant then came in the next day for ABPM device collection, and this visit marked the first day of treatment with Perindopril 10 $\mathrm{mg}$ with each pack containing 30 tablets. The morning dose of perindopril $10 \mathrm{mg}$ was taken between $7 \mathrm{am}-9$ am while the evening dose was taken at $20 \mathrm{pm} \pm 1 \mathrm{~h}$. Participants were requested to attend follow-up visits with their tablet boxes. The second investigator was then able to verify adherence to the treatment by counting the remaining tablets in the original box.

On day 28 , all the biological analyses done on day 0 were repeated, a new ABPM was performed. At the end of this measure, drug regimen was switched for each group and the participant continued the new regimen for 28 other days. At the end of the 56 days of perindopril treatment, all the previous analyses were repeated and the final ABPM recorded.

\section{Outcomes measures}

The primary outcome was the change in average 24hour systolic ABPM. Other outcomes included changes in 24-hour DBP, MAP and PP, change in daytime and night time SBP and DBP, change in urinary albumin excretion, serum uric acid and plasma potassium.

Tolerability and side effects were evaluated taking into account events spontaneously reported by participants, recorded in response to an open question or observed by investigator during visits.

\section{Statistical analysis}

Variation in SBP was used for the estimation of minimal sample size. The study was designed to detect a $10 \mathrm{mmHg}$ absolute difference (standard deviation = 10 ) in SBP between regimens [19]. For an $80 \%$ power and $5 \%$ significance level, at least six participants were required per study arm [20]. This number was increased to 10 , in anticipation of a $25 \%$ loss to follow-up, giving a total of 20 participants across the two arms.

Data were analyzed using $\mathrm{R}^{\circledR}$ version 3.3 .3 (2017-0306) [The R Foundation for Statistical Computing] and IBM SPSS for Windows, version 21.0 for Windows (IBM SPSS Statistics for Windows, Armonk, NY: IBM Corp.). The paired-sample t-test and Wilcoxon test were used to assess differences by treatment strategy, in the changes in mean levels of continuous variables during follow-up, while the McNemar test was used to assess difference in the occurrence of binary outcomes. A test for carry-over effects following Kenward and Jones revealed no carryover effects between the two treatment periods [21]. A $p$-value $<0.05$ was used to characterize statistically significant results.

\section{Results}

\section{Baseline characteristics}

During the study period, a total of 50 patients were examined of which 35 were eligible. Among the 35 eligible patients, four were living out of the town and five refused to participate, six patients presented white coat hypertension after initial $24 \mathrm{~h}$ ABPM was performed. So, we enrolled twenty patients (11 men), with a mean age of $58.7 \pm 9.6$ years. They were allocated randomly to the study therapy regimens with 10 patients in each group as shown in Figure 1. After 28 days, three patients were excluded: One presenting systolic blood pressure greater than $160 \mathrm{mmHg}$ despite the treatment, and two lost during follow-up.

Our sample at the final visit therefore comprised 17 participants with 8 in the morning-evening group and 9 in the evening-morning group. Median $\left[25^{\text {th }}\right.$ $75^{\text {th }}$ percentiles] diabetes duration and glycated

Table 1: Baseline Demographic Characteristics of Study Population $(n=20)$.

\begin{tabular}{|l|l|l|l|}
\hline Characteristics & Overall & Men & Women \\
\hline Female, $\mathrm{n}(\%)$ & $9(45)$ & $11(55)$ & $9(45)$ \\
\hline Age, $\mathrm{y}$ & $57.5[54.0-65.2]$ & $57.0[48.0-58.0]$ & $66.0[54.5-73.5]$ \\
\hline Diabetes mellitus duration, $\mathrm{y}$ & $2.0[0.75-9.75]$ & $2.0[0.2-9.0]$ & $4.0[0.8-13.0]$ \\
\hline $\mathrm{HbA}_{1 \mathrm{c}} \%$ & $7.9[6.8-13.1]$ & $7.4[7.0-8.1]$ & $13.1[6.4-14.2]$ \\
\hline${\text { Body mass index, } \mathrm{kg} / \mathrm{m}^{2}}^{2}$ & $27.2[23.4-30.6]$ & $28.7[26.4-30.8]$ & $26.6[19.7-30.0]$ \\
\hline 24-hour systolic BP, $\mathrm{mmHg}$ & $137.0[129.7-149.2]$ & $137.0[130.5-149.2]$ & $137.0[127.7-149.7]$ \\
\hline 24-hour diastolic BP, $\mathrm{mmHg}$ & $84.5[77.7-88.2]$ & $87.0[80.2-89.2]$ & $81.5[77.0-87.7]$ \\
\hline 24-hour mean BP, $\mathrm{mmHg}$ & $102.3[96.8-109.0]$ & $103.6[96.8-108.5]$ & $97.5[96.2-109.0]$ \\
\hline Systolic office BP, $\mathrm{mmHg}$ & $141.5[139.0-152.0]$ & $149.0[139.0-152.0]$ & $141.0[138.5-156.0]$ \\
\hline Diastolic office BP, $\mathrm{mmHg}$ & $93.0[85.2-93.0]$ & $95.0[93.0-101.0]$ & $89.0[84.0-98.5]$ \\
\hline Nocturnal blood pressure fall, \% & $1.7[-5.2-5.7]$ & $1.0[0.9-1.0]$ & $1.0[0.9-1.0]$ \\
\hline Dip pattern, $\mathrm{n}$ (\%) & $2(11)$ & $1(10)$ & $1(10)$ \\
\hline Albumin/creatinine ratio, $\mathrm{mg} / \mathrm{g}$ & $132.6[71.1-229.0]$ & $111.5[61.5-214.4]$ & $140.1[81.4-280.3]$ \\
\hline Uric acid, g/l & $51.7[47.0-56.0]$ & $54.3[51.2-64.0]$ & $47.7[42.6-50.8]$ \\
\hline
\end{tabular}

Values are medians and $25^{\text {th }}-75^{\text {th }}$ percentiles or count and percentages; BP: Blood pressure; HbA 1 : Glycated haemoglobin. 
haemoglobin (HbA1c) were respectively 2 [0.7-9.7] years and $7.9 \%$ [6.8-13.1]. 40\% of participants were overweight and $30 \%$ obese. Median BMI was 27.2 [23.4-30.6] kg/m². Baseline characteristics of the study population are summarised in Table 1.

\section{Effect of each administration scheme on blood pressure and heart rate}

The change in mean 24-hour SBP between the first and second treatment periods was $-0.8(S D=3.5) \mathrm{mmHg}$ in the morning-evening perindopril sequence allocation, and $-2.6(9.5) \mathrm{mmHg}$ in the evening-morning sequence allocation group. The treatment effect was $-1.8(95 \%$ $\mathrm{Cl}:-5.4$ to 1.9$) \mathrm{mmHg}, \mathrm{p}=0.61$ for the paired-sample $t$-test, indicating no statistical difference in the effect of morning and evening perindopril on 24-hour SBP (Table 2). There was also no difference in the treatment effect on 24-hour DBP $(p=0.46)$, 24-hour MAP ( $p=0.32)$, 24hour pulse pressure $(p=0.94)$ and $24-h$ heart rate $(p=$ 0.86), Table 2.

Table 2: Outcome measures and treatment sequence allocation.

\begin{tabular}{|c|c|c|c|c|c|}
\hline \multirow[t]{2}{*}{ Outcome } & \multirow{2}{*}{$\begin{array}{l}\text { Treatment } \\
\text { sequence }\end{array}$} & \multirow[t]{2}{*}{ Estimates } & \multicolumn{2}{|c|}{ Treatment period } & \multirow{2}{*}{$\begin{array}{l}\text { Within individual difference: } \\
\text { Morning-evening }\end{array}$} \\
\hline & & & 1 & 2 & \\
\hline & & & Period 1 & Period 2 & \\
\hline \multicolumn{6}{|l|}{ 24-hour BP } \\
\hline \multirow[t]{8}{*}{ SBP } & Morning-evening & Mean (SD) & $129.3(14.2)$ & $130.5(15.1)$ & $-0.8(3.5)$ \\
\hline & & Sample size & 9 & 8 & 8 \\
\hline & Evening-morning & Mean (SD) & $139.0(14.1)$ & $132.6(12.0)$ & $-2.6(9.5)$ \\
\hline & & Sample size & 10 & 9 & 9 \\
\hline & Treatment effect & Mean (SD) & & & $-1.8(7.1)$ \\
\hline & & $95 \% \mathrm{Cl}$ & & & -5.4 to 1.9 \\
\hline & & Sample size & & & 17 \\
\hline & & Paired sample t-test & & & 0.61 \\
\hline \multirow[t]{8}{*}{ DBP } & Morning-evening & Mean (SD) & $78.2(8.0)$ & $77.7(8.1)$ & $0.2(2.8)$ \\
\hline & & Sample size & 9 & 8 & 8 \\
\hline & Evening-morning & Mean (SD) & $86.2(9.9)$ & $82.2(10.1)$ & $-2.0(7.8)$ \\
\hline & & Sample size & 10 & 9 & 9 \\
\hline & Treatment effect & Mean (SD) & & & $-0.9(5.9)$ \\
\hline & & $95 \% \mathrm{Cl}$ & & & -4.0 to 2.1 \\
\hline & & Sample size & & & 17 \\
\hline & & Paired sample t-test & & & 0.46 \\
\hline \multirow[t]{8}{*}{ MAP } & Morning-evening & Mean (SD) & $95.2(10.5)$ & $95.3(9.9)$ & $-0.1(2.8)$ \\
\hline & & Sample size & 9 & 8 & 8 \\
\hline & Evening-morning & Mean (SD) & $100.3(7.3)$ & $99.0(10.3)$ & $-3.2(8.1)$ \\
\hline & & Sample size & 10 & 9 & 9 \\
\hline & Treatment effect & Mean (SD) & & & $-1.7(6.0)$ \\
\hline & & $95 \% \mathrm{Cl}$ & & & -4.5 to 1.6 \\
\hline & & Sample size & & & 17 \\
\hline & & Paired sample t-test & & & 0.32 \\
\hline \multirow[t]{8}{*}{ Pulse pressure } & Morning-evening & Mean (SD) & $51.2(7.3)$ & $52.4(7.4)$ & $-0.5(2.0)$ \\
\hline & & Sample size & 9 & 8 & 8 \\
\hline & Evening-morning & Mean (SD) & $52.6(8.7)$ & $50.5(6.7)$ & $-0.6(4.4)$ \\
\hline & & Sample size & 10 & 9 & 9 \\
\hline & Treatment effect & Mean (SD) & & & $-0.5(3.4)$ \\
\hline & & $95 \% \mathrm{Cl}$ & & & -2.3 to 1.2 \\
\hline & & Sample size & & & 17 \\
\hline & & Paired sample t-test & & & 0.94 \\
\hline \multirow[t]{8}{*}{ Heart rate } & Morning-evening & Mean (SD) & $80(8)$ & $79(6)$ & $1(3)$ \\
\hline & & Sample size & 9 & 8 & 8 \\
\hline & Evening-morning & Mean (SD) & $79(6)$ & $78(14)$ & $-2(10)$ \\
\hline & & Sample size & 10 & 9 & 9 \\
\hline & Treatment effect & Mean (SD) & & & $-1(7)$ \\
\hline & & $95 \% \mathrm{Cl}$ & & & -5 to 2 \\
\hline & & Sample size & & & 17 \\
\hline & & Paired sample t-test & & & 0.86 \\
\hline \multirow{3}{*}{$\begin{array}{l}\text { Nocturnal dip in SBP } \\
(\%)\end{array}$} & Morning-evening & Mean (SD) & $-0.4(7.7)$ & $2.9(7.4)$ & $-3.3(7.6)$ \\
\hline & & Sample size & 9 & 8 & 8 \\
\hline & Evening-morning & Mean (SD) & $1.3(7.2)$ & $-7.1(8.6)$ & $-6.4(14.5)$ \\
\hline
\end{tabular}




\begin{tabular}{|c|c|c|c|c|c|}
\hline & & Sample size & 10 & 9 & 9 \\
\hline & Treatment effect & Mean (SD) & & & $-4.9(11.5)$ \\
\hline & & $95 \% \mathrm{Cl}$ & & & -10.9 to 1.0 \\
\hline & & Sample size & & & 17 \\
\hline & & Paired sample t-test & & & 0.60 \\
\hline \multirow{8}{*}{$\begin{array}{l}\text { Nocturnal dip in DBP } \\
(\%)\end{array}$} & Morning-evening & Mean (SD) & $-3.0(7.0)$ & $0.5(5.7)$ & $-3.3(5.7)$ \\
\hline & & Sample size & 9 & 8 & 8 \\
\hline & Evening-morning & Mean (SD) & $-6.5(4.4)$ & $-6.5(13.0)$ & $-0.5(16.7)$ \\
\hline & & Sample size & 10 & 9 & 9 \\
\hline & Treatment effect & Mean (SD) & & & $-1.8(12.5)$ \\
\hline & & $95 \% \mathrm{Cl}$ & & & -8.2 to 4.6 \\
\hline & & Sample size & & & 17 \\
\hline & & Paired sample t-test & & & 0.65 \\
\hline \multirow[t]{8}{*}{ FVSNsysto } & Morning-evening & Mean (SD) & $19.7(23.1)$ & $21.1(32.2)$ & $-12.1(32.8)$ \\
\hline & & Sample size & 9 & 8 & 8 \\
\hline & Evening-morning & Mean (SD) & $36.6(26.8)$ & $26.9(21.1)$ & $-3.1(19.7)$ \\
\hline & & Sample size & 10 & 9 & 9 \\
\hline & Treatment effect & Mean (SD) & & & $-5.4(22.2)$ \\
\hline & & $95 \% \mathrm{Cl}$ & & & -19.5 to 8.7 \\
\hline & & Sample size & & & 17 \\
\hline & & Paired sample t-test & & & 0.57 \\
\hline \multirow[t]{8}{*}{ UACR } & Morning-evening & Mean (SD) & $\begin{array}{l}150.2 \\
(119.5)\end{array}$ & $139.1(96.5)$ & $-29.6(88.9)$ \\
\hline & & Sample size & 9 & 8 & 8 \\
\hline & Evening-morning & Mean (SD) & $\begin{array}{l}158.2 \\
(123.5)\end{array}$ & $113.9(68.8)$ & $-52.4(111.3)$ \\
\hline & & Sample size & 10 & 9 & 9 \\
\hline & Treatment effect & Mean (SD) & & & $-41.7(99.0)$ \\
\hline & & $95 \% \mathrm{Cl}$ & & & -92.6 to 9.2 \\
\hline & & Sample size & & & 17 \\
\hline & & $\begin{array}{l}\text { Paired sample Wilcoxon } \\
\text { test }\end{array}$ & & & 0.58 \\
\hline \multirow[t]{8}{*}{ Uric acid } & Morning-evening & Mean (SD) & $59.1(8.4)$ & $55.9(9.2)$ & $3.2(7.9)$ \\
\hline & & Sample size & 9 & 8 & 8 \\
\hline & Evening-morning & Mean (SD) & $51.5(7.8)$ & $51.0(8.5)$ & $-0.4(6.7)$ \\
\hline & & Sample size & 10 & 9 & 9 \\
\hline & Treatment effect & Mean (SD) & & & $1.3(7.3)$ \\
\hline & & $95 \% \mathrm{Cl}$ & & & -2.5 to 5.1 \\
\hline & & Sample size & & & 17 \\
\hline & & Paired sample t-test & & & 0.32 \\
\hline \multicolumn{6}{|l|}{ Daytime ABPM } \\
\hline \multirow[t]{8}{*}{ SBP } & Morning-evening & Mean (SD) & $129.5(13.7)$ & $120.0(13.0)$ & $1.1(4.4)$ \\
\hline & & Sample size & 9 & 8 & 8 \\
\hline & Evening-morning & Mean (SD) & $139.2(15.7)$ & $134.0(14.5)$ & $-1.2(12.1)$ \\
\hline & & Sample size & 10 & 9 & 9 \\
\hline & Treatment effect & Mean (SD) & & & $-0.1(9.1)$ \\
\hline & & $95 \% \mathrm{Cl}$ & & & -4.8 to 4.6 \\
\hline & & Sample size & & & 17 \\
\hline & & Paired sample t-test & & & 0.63 \\
\hline \multirow[t]{8}{*}{ DBP } & Morning-evening & Mean (SD) & $78.4(8.2)$ & $78.1(9.1)$ & $-0.04(2.01)$ \\
\hline & & Sample size & 9 & 8 & 8 \\
\hline & Evening-morning & Mean (SD) & $87.4(10.4)$ & $82.2(12.8)$ & $-3.1(11.4)$ \\
\hline & & Sample size & 10 & 9 & 9 \\
\hline & Treatment effect & Mean (SD) & & & $-1.7(8.3)$ \\
\hline & & $95 \% \mathrm{Cl}$ & & & -5.9 to 2.6 \\
\hline & & Sample size & & & 17 \\
\hline & & Paired sample t-test & & & 0.47 \\
\hline \multirow[t]{4}{*}{ Heart rate } & Morning-evening & Mean (SD) & $83(9)$ & $82(7)$ & $-1(3)$ \\
\hline & & Sample size & 9 & 8 & 8 \\
\hline & Evening-morning & Mean (SD) & $80(6)$ & $79(14)$ & $-1(13)$ \\
\hline & & Sample size & 10 & 9 & 9 \\
\hline
\end{tabular}




\begin{tabular}{|c|c|c|c|c|c|}
\hline & Treatment effect & Mean (SD) & & & $-1(9)$ \\
\hline & & $95 \% \mathrm{Cl}$ & & & \\
\hline & & Sample size & & & 17 \\
\hline & & Paired sample t-test & & & 0.97 \\
\hline \multicolumn{6}{|c|}{ Nightime ABPM } \\
\hline \multirow[t]{8}{*}{ SBP } & Morning-evening & Mean (SD) & $128.5(16.2)$ & $132.2(17.0)$ & $-4.0(9.3)$ \\
\hline & & Sample size & 9 & 8 & 8 \\
\hline & Evening-morning & Mean (SD) & $136.7(12.3)$ & $129.6(10.1)$ & $-4.1(8.7)$ \\
\hline & & Sample size & 10 & 9 & 9 \\
\hline & Treatment effect & Mean (SD) & & & $-4.1(8.7)$ \\
\hline & & $95 \% \mathrm{Cl}$ & & & -8.6 to 0.4 \\
\hline & & Sample size & & & 17 \\
\hline & & Paired sample t-test & & & 0.98 \\
\hline \multirow[t]{8}{*}{ DBP } & Morning-evening & Mean (SD) & $76.5(11.3)$ & $77.0(11.9)$ & $-1.3(3.1)$ \\
\hline & & Sample size & 9 & 8 & 8 \\
\hline & Evening-morning & Mean (SD) & $81.3(8.3)$ & $80.4(8.3)$ & $0.6(8.3)$ \\
\hline & & Sample size & 10 & 9 & 9 \\
\hline & Treatment effect & Mean (SD) & & & $-0.3(6.3)$ \\
\hline & & $95 \% \mathrm{Cl}$ & & & -3.5 to 3.0 \\
\hline & & Sample size & & & 17 \\
\hline & & Paired sample t-test & & & 0.55 \\
\hline \multirow[t]{8}{*}{ Heart rate } & Morning-evening & Mean (SD) & $72(8)$ & $73(7)$ & $-1(5)$ \\
\hline & & Sample size & 9 & 8 & 8 \\
\hline & Evening-morning & Mean (SD) & $74(12)$ & $73(14)$ & $-2(5)$ \\
\hline & & Sample size & 10 & 9 & 9 \\
\hline & Treatment effect & Mean (SD) & & & $-1(5)$ \\
\hline & & $95 \% \mathrm{Cl}$ & & & -4 to 1 \\
\hline & & Sample size & & & 17 \\
\hline & & Paired sample t-test & & & 0.70 \\
\hline \multicolumn{6}{|l|}{ Others } \\
\hline \multirow[t]{8}{*}{ Kalemia } & Morning-evening & Mean (SD) & $4.9(0.4)$ & $5.0(0.4)$ & $0.04(0.10)$ \\
\hline & & Sample size & 9 & 8 & 8 \\
\hline & Evening-morning & Mean (SD) & $4.9(0.4)$ & $4.8(0.4)$ & $-0.05(0.64)$ \\
\hline & & Sample size & 10 & 9 & 9 \\
\hline & Treatment effect & Mean (SD) & & & $-0.005(0.464)$ \\
\hline & & $95 \% \mathrm{Cl}$ & & & -0.244 to 0.233 \\
\hline & & Sample size & & & 17 \\
\hline & & Paired sample t-test & & & 0.67 \\
\hline
\end{tabular}

The nocturnal dip in SBP was $-0.4 \%$ (SD 7.7) and 2.9\% (7.4) respectively and the end of the first and second treatment periods in the morning-evening sequence group. Equivalent figures were $1.3 \%$ (7.2) and -7.15 (8.6) in the evening-morning sequence group. The within-individual difference (morning-evening) was $-3.3 \%(S D=7.6)$ and $-6.4 \%(14.5)$ respectively within the morning-evening and evening-morning sequence groups. The treatment effect was $-4.9 \%(95 \% \mathrm{Cl}-10.9$ to 1.0), indicating again a non-significant difference in SBP dipping by time of treatment administration (paired-sample t-test $p=0.60$ ). The treatment effect on nocturnal DBP dipping was also non-significant: $-1.8 \%(95 \% \mathrm{Cl}-8.2$ to $4.6 ; \mathrm{p}=0.65)$; Table 2. Treatment effects on daytimes and nighttime BP and heart rate are available in Table 2, always in support of no significant treatment effect (all $p \geq 0.47$ ).

Effect of each administration scheme serum
potassium, uric acid and urinary albumin excretion

The within-individual difference in serum potassium between the two treatment periods (morning-evening) was 0.04 (SD $=0.10)$ and $-0.05(0.64)$ respectively in the morning-evening and evening-morning sequence groups. The treatment effect of $-0.005(95 \% \mathrm{Cl}-0.244$ to 0.233$)$, was not statistically significant $(p=0.67)$. Treatment effects on uric acid level $(p=0.32)$, urinary albumin excretion $(p=0.58)$ were also non-significant (Table 2).

\section{Side effects}

Headaches were recorded in $1 / 8$ participants during morning perindopril and in $3 / 10$ participants during evening perindopril, with a $p$-value of 0.62 for the McNemar test, indicating no differential occurrence of headaches by treatment regimen. Cough was recorded in $2 / 8$ participants during morning perindopril and in $1 / 10$ participants during evening perindopril with a $p$-value $>0.99$. Vertigo was reported in $2 / 10$ participants only during the evening with a $p$-value of 0.48 . Hence the McNemar test indicated no differential occurrence of cough and vertigo by treatment regimen (Table 3 ). 
Table 3: Outcome measures, side effects and treatment sequence allocations.

\begin{tabular}{|c|c|c|c|c|c|}
\hline \multirow[t]{2}{*}{ Outcome } & \multirow{2}{*}{$\begin{array}{l}\text { Treatment } \\
\text { sequence }\end{array}$} & \multirow[t]{2}{*}{ Estimates } & \multicolumn{2}{|c|}{ Treatment period } & \multirow[t]{2}{*}{ Mc-Memar test (p-value) } \\
\hline & & & 1 & 2 & \\
\hline & & & Period 1 & Period 2 & \\
\hline \multirow[t]{4}{*}{ Headache } & Morning-evening & $\mathrm{N}$ & 1 & 0 & 0.62 \\
\hline & & Sample size & 8 & 8 & \\
\hline & Evening-morning & $\mathrm{N}$ & 3 & 0 & \\
\hline & & Sample size & 10 & 9 & $>0.99$ \\
\hline \multirow[t]{4}{*}{ Cough } & Morning-evening & $\mathrm{N}$ & 2 & 0 & \\
\hline & & Sample size & 8 & 8 & \\
\hline & Evening-morning & $\mathrm{N}$ & 1 & 0 & \\
\hline & & Sample size & 10 & 9 & \\
\hline \multirow[t]{4}{*}{ Lipothymia } & Morning-evening & $\mathrm{N}$ & 0 & 0 & NA \\
\hline & & Sample size & 8 & 8 & \\
\hline & Evening-morning & $\mathrm{N}$ & 0 & 0 & \\
\hline & & Sample size & 10 & 9 & \\
\hline \multirow[t]{4}{*}{ Vertigo } & Morning-evening & $\mathrm{N}$ & 0 & 0 & 0.48 \\
\hline & & Sample size & 8 & 8 & \\
\hline & Evening-morning & $\mathrm{N}$ & 2 & 0 & \\
\hline & & Sample size & 10 & 9 & \\
\hline
\end{tabular}

\section{Discussion}

This study was carried out to investigate the chronotherapeutic effect of perindopril on blood pressure control in sub-Saharan type 2 diabetes mellitus population with stage 1 hypertension naïve to antihypertensive treatment. We found that morning administration of perindopril in both treatment sequences has no significant effect over evening regimen on blood pressure levels, hear rate, potassium and uric acid levels, as well as urinary albumin excretion and side effects including cough, headache, vertigo and lipothymia. Findings for some outcomes however, were limited by the small sample size. Hermida RC, et al. [22] described that the bedtime administration of ACEls has been shown to be more beneficial since they exert a more marked effect on the asleep than awake SBP and DBP. This was however not verified in our study. Possible explanations could be our limited sample size but also the long independent drug terminal half-life of Perindopril [23] may exert the same effect when taking as a morning or an evening dose.

Many studies have investigated the effect of perindopril on circadian control of blood pressure levels [24-26]. However, to the best of our knowledge, this is the first study comparing chronotherapeutic schemes of perindopril in hypertensive patients using a crossover design. The urinary albumin/creatinine ratio which is a marker of chronic kidney disease reduced overtime following the administration of 10 mg Perindopril no matter the treatment sequence considered confirming the reno-protective effects of ACE inhibitors in hypertensive patients with type 2 diabetes [27]. Considering the importance of ACEI for kidney preservation and the fact that diuretics and calcium antagonists are more efficient in sub-Saharan patients, we postulate that the ideal combination for BP control in these patients must contain an ACEl added to one of the above molecules $[14,28,29]$.

The implications of our findings can be of great clinical significance for physicians who could align the treatment of certain patients to best fit their daily routine activities and work schedule without losing the therapeutic effect of the perindopril. Patients on perindopril who missed morning dose can be advised to catch up in the evening without fear of any compromise. Patients with multiple morbidities and who are polymedicated can be advised to take other medications as usual in the morning and perindopril in the evening in order to reduce the pill burden associated with poly-medication. Patients on fixed-dose combination containing perindopril and maybe diuretic may be encouraged to take the combination in the morning so as to reduce the number of waking at night to urinate usually associated with the night time administration of diuretics.

It is worth noting that the small sample size of this study may limit the generalization of the findings of this study to all sub-Saharan populations. However the cross-over design and the simultaneous treatment sequence allocation analysis and comparison provide a solid appraisal of the effect of the different times of administrations of perindopril.

\section{Conclusions}

This study revealed no difference in the effects of daytime vs. evening time administration of perindopril on BP levels in sub-Saharan type 2 diabetes patients with grade I hypertension. This confirms that in this group of patients, the administration of perindopril can be prescribed based on the preference of the patient with regards to time of day without fear of lowering the clinical effect.

\section{Acknowledgement}

All the participants who took part in the study and 
the medical and para-medical staff of the National Obesity Center of the Yaoundé Central Hospital, Cameroon.

\section{Sources of Support}

No external funding was received for this study.

\section{References}

1. Tankeu AT, Noubiap JJ (2016) Oscillating blood pressure therapeutic target in type 2 diabetes patients with hypertension. Ann Transl Med 4: 422.

2. Sowers JR, Epstein M, Frohlich ED (2001) Diabetes, hypertension, and cardiovascular disease: An update. Hypertension 37: 1053-1059.

3. Adler AI, Stratton IM, Neil HAW, Yudkin JS, Matthews DR, et al. (2000) Association of systolic blood pressure with macrovascular and microvascular complications of type 2 diabetes (UKPDS 36): Prospective observational study. BMJ 321: 412-419.

4. Vijan S, Hayward RA (2003) Treatment of hypertension in type 2 diabetes mellitus: Blood pressure goals, choice of agents, and setting priorities in diabetes care. Ann Intern Med 138: 593-602.

5. Tankeu AT, Mfeukeu Kuate L, Nganou Gnindjio CN, Ankotché A, Leye A, et al. (2017) Spécificités de la prise en charge de l'hypertension artérielle chez le patient diabétique sub-saharien. Médecine des Maladies Métaboliques 11: 148-154.

6. Nong-Libend C, Menanga AP, Kengne AP, Dehayem M, Sobngwi E, et al. (2012) High levels of discordance between office-based and ambulatory blood pressure measurements for diagnosing optimal blood pressure control in high-risk diabetic populations from a developing country. Diabetes Metab 38: 271-272.

7. Jan A Staessen, Lutgarde Thijs, Robert Fagard, Eoin T O'Brien, Denis Clement, et al. (1999) Predicting cardiovascular risk using conventional vs ambulatory blood pressure in older patients with systolic hypertension. JAMA 282: 539-546.

8. Staessen JA, Thijs L, Fagard R, O'Brien ET, Clement D, et al. (1999) Predicting cardiovascular risk using conventional vs ambulatory blood pressure in older patients with systolic hypertension. Systolic Hypertension in Europe Trial Investigators. JAMA 282: 539-546.

9. Gonzalez E, Hernandez A, Dibner C, B Koehler Ballan, A Pechère-Bertschi (2012) Implications cliniques du cycle circadien de la pression artérielle. Revue Médicale Suisse 8: 1709-1715.

10. White WB (1992) Diurnal blood pressure and blood pressure variability in diabetic normotensive and hypertensive subjects. J Hypertens Suppl 10: S35-S41.

11. Bernardi S, Michelli A, Zuolo G, Candido R, Fabris B (2016) Update on RAAS modulation for the treatment of diabetic cardiovascular disease. J Diabetes Res.

12. Standards of medical care in diabetes-2016: Summary of revisions. Diabetes Care 39: S4-S5.

13. Moyá A, Crespo JJ, Ayala DE, Ríos MT, Pousa L, et al (2013) Effects of time-of-day of hypertension treatment on ambulatory blood pressure and clinical characteristics of patients with type 2 diabetes. Chronobiol Int 30: 116-131.

14. Todd PA, Fitton A (1991) Perindopril. A review of its pharmacological properties and therapeutic use in cardiovascular disorders. Drugs 42: 90-114.
15. Dahjio Y, Noubiap JJ, Azabji-Kenfack M, Essouma M, Loni GE, et al. (2016) Impact of a 12-week aerobic exercise training program on anthropometric and metabolic parameters of a group of type 2 diabetes cameroonian women aged $\geq 50$ years. Ann Transl Med 4: 364 .

16. National High Blood Pressure Education Program (2004) The seventh report of the joint national committee on prevention, detection, evaluation, and treatment of high blood pressure. National Heart, Lung, and Blood Institute (US).

17. Organisation Mondiale de la santé (2003) Méthodologie de la recherche dans le domaine de la santé: Guide de formation aux méthodes de la recherche scientifique. Manille, OMS.

18. Agoons DD, Balti EV, Kaze FF, Azabji-Kenfack M, Ashuntantang G, et al. (2016) Performance of three glomerular filtration rate estimation equations in a population of sub-Saharan Africans with Type 2 diabetes. Diabet Med 33: 1291-1298.

19. R Turner, UK Prospective Diabetes Study Group (1998) Tight blood pressure control and risk of macrovascular and microvascular complications in type 2 diabetes: UKPDS 38. BMJ 317: 703

20. Whitley E, Ball J (2002) Statistics review 4: Sample size calculations. Crit Care 6: 335-341.

21. Kenward MG, Jones B (1987) The analysis of data from 2 $\times 2$ cross-over trials with baseline measurements. Stat Med 6: 911-926.

22. Hermida RC, Ayala DE, Fernández JR, Mojón A, Smolensky $\mathrm{MH}$, et al. (2013) Administration-time differences in effects of hypertension medications on ambulatory blood pressure regulation. Chronobiol Int 30: 280-314.

23. Thomson A, Greenacre M (2007) Perindopril: The evidence of its therapeutic impact in hypertension. Core Evid 2: 63-79.

24. Kuwajima I, Fujisawa A, Mitani K, Suzuki Y, Kuramoto K (1994) Effect of perindopril on 24-hour blood pressure levels and hemodynamic responses to physical and mental stress in elderly hypertensive patients. Clin Ther 16: 962-971.

25. Ionescu D-D, PREFER Investigators (2009) Antihypertensive efficacy of perindopril 5-10 mg/day in primary health care: An open-label, prospective, observational study. Clin Drug Investig 29: 767-776.

26. Yamamoto $\mathrm{Y}$, Oiwa $\mathrm{K}$, Hayashi M, Ohara T, Muranishi $M$ (2005) Effect of the angiotensin-converting enzyme inhibitor perindopril on 24-hour blood pressure in patients with lacunar infarction: Comparison between dippers and non-dippers. Hypertens Res 28: 571-578.

27. Baltatzi M, Savopoulos C, Hatzitolios A (2011) Role of angiotensin converting enzyme inhibitors and angiotensin receptor blockers in hypertension of chronic kidney disease and renoprotection. Study results. Hippokratia 15: 27-32.

28. Wang JG, Pimenta E, Chwallek F (2014) Comparative review of the blood pressure-lowering and cardiovascular benefits of telmisartan and perindopril. Vasc Health Risk Manag 10: 189-200.

29. James PA, Oparil S, Carter BL, Cushman WC, DennisonHimmelfarb C, et al. (2014) 2014 Evidence-based guideline for the management of high blood pressure in adults: Report from the panel members appointed to the eighth joint national committee (JNC 8). JAMA 311: 507-520.
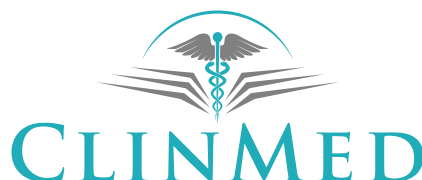

INTERNATIONAL LIBRARY 